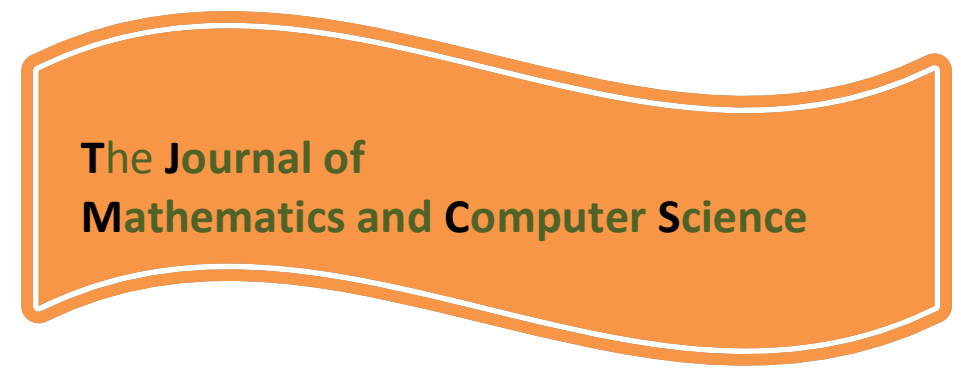

Available online at

\title{
http://www.TJMCS.com
}

The Journal of Mathematics and Computer Science Vol. 4 No.2 (2012) 110 - 119

\section{Business Intelligence maturity model in organization on the base of the capability maturing model (CMM)}

\author{
Mahdi Sayyadi*1, Emad Farazmand², Omid Gholami ${ }^{3}$ \\ 1 Department of Computer Engineering, Islamic Azad University, Mahshahr Branch, Mahshahr, Iran \\ Sayyadi.mahdi @gmail.com \\ 2 Department of Computer Engineering, Islamic Azad University, Mahshahr Branch, Mahshahr, Iran, \\ e.farazmand @gmail.com \\ 3 Department of Computer Engineering, Islamic Azad University, Mahshahr Branch, Mahshahr, Iran \\ Gholami@kssco.ir
}

Received: January 2012, Revised: April 2012

Online Publication: June 2012

\begin{abstract}
This is more than a decade that organizations for establishing and taking part the system due to importing and have a better decision they have to stand on and tolerate expenses .Establishing and taking part is one of the problems and in other hand the quality of this systems is another problem .During this essay we have used capacity maturing model which have been used before in software improvement management which is includes of these five levels: initial repeatable , Defined, something which has been managed before and in last stage it should be something which has been optimized. In this essay we are going to analyze and examine them is six aspects, which are include of data quality, data warehouse architecture, information technology, analysis and analysis culture or behavior management strategies.
\end{abstract}

\footnotetext{
* Corresponding Author
} 
This model helps organizations to make the first step in the maturity model to determine its position, and then the next step is preliminary and needs to achieve higher levels of maturing to get and understand completely.

Keywords: Business intelligence, Business intelligence maturing model, capability maturing model (CMM)

\section{INTRODUCTION}

(Business intelligence is among the topics that has received a much attention in recent years because of its Strategic role in organizations. In fact the huge range of business intelligence technology, tools, a set of processes for the collection, storage, access and analyze data is for helping the users due to take a good and effective decisions[1].

Another defined set of business intelligence, progresses, technology and tools needed to transform data into information, information into knowledge and knowledge to set up and plans for business is profitable.[2]

Implementation of business intelligence in organization due to the completely and site is one of the major challenges organizations.

It's position in the maturity levels of organizations one very eager to know and understand their place requirements to achieve higher levels. Therefore in recent years several models one presented for each various aspects of it one considered. The model of the capability maturing model is a framework for describing the evolution and incomplete process, which is involved into a regular and irregular process and various aspects of business intelligence has been studied.

\section{THE MODEL DESCRIPTION}

This model is combining the capability maturity model (CMM) and levels of business intelligence in organizations. This is actually the CMM origin in November 1986, software engineering institute (SEI) began to develop a framework. For the maturity of software organization can use to recreate the content of software development in their own software. In September 1987; ISE has published a brief description of the process maturity framework that was developed later and was released as process management software first stages of development defined in the CMM for software which is include: elementary repeatability , defined, managed and be able to optimized at the initial level may be used in almost any organization can be said that law is not employed, and sometimes also caused 
success depends on the personal courage to try. Repeatability is a process that is regulated to some extent the organization can prove your previous successes in similar situation to repeat. At this level of defined activity in the engineering and process management software, in the form of software process has been classification, standardization and integrated. To develop and maintain software, at first a copy of all projects and use separate organizational standard process should prepare. In fact in this stage on the base of relative laws we can say that prevails in the guide line, procedures and standard have been defined, and services can be provided at this stage to give a cohere, organized and promoted detailed steps in the management software, software process and overall product quality and content is understood as the quality and we can say that the organization is an a position that can indentify quantifiable quality objective and enhance it can it can involve the quality of quality. In place to optimize the organization and technology can offer new services while upgrades and going. Six model of various aspects of data quality, data warehouse architecture, information technology, and data analysis, culture, or behavior management strategies and plan will be examined. Different aspects of the model along with brief description in table 1 has been shown.

Table1. Different aspects of the model

\begin{tabular}{|l|l|}
\hline \multicolumn{1}{|c|}{ Factors: } & \multicolumn{1}{c|}{ Description: the include of the } \\
\hline $\begin{array}{l}\text { Information } \\
\text { Quality }\end{array}$ & $\begin{array}{l}\text { Quality of information which is available for uses and also } \\
\text { process at every level of the index that is determined to } \\
\text { reinforce information. }\end{array}$ \\
\hline $\begin{array}{l}\text { Warehousing } \\
\text { Architecture }\end{array}$ & $\begin{array}{l}\text { Maturation and storage of data at every level of its } \\
\text { architecture. }\end{array}$ \\
\hline $\begin{array}{l}\text { Information } \\
\text { Technology }\end{array}$ & $\begin{array}{l}\text { The amount of work in each of the levels of IT tools and } \\
\text { potential. }\end{array}$ \\
\hline Analytics & $\begin{array}{l}\text { Development of capabilities in the field of organizational } \\
\text { analysis. }\end{array}$ \\
\hline $\begin{array}{l}\text { Culture or } \\
\text { Behavior }\end{array}$ & $\begin{array}{l}\text { People paints of new about organization as well as business } \\
\text { intelligence and the level of making decision of achievement } \\
\text { in business intelligence and other matters. }\end{array}$ \\
\hline $\begin{array}{l}\text { Strategy and } \\
\text { Program } \\
\text { Management }\end{array}$ & $\begin{array}{l}\text { Progress of project and business intelligence projects in each } \\
\text { level. }\end{array}$ \\
\hline
\end{tabular}




\section{THE MODEL PRESENTED}

For presenting the maturing model, Hewlett Pakard (HP), Eckerson (TDWI), Gartner, AMR models have been examined. Business intelligence maturing model placed in each of the parties and characteristics of each level is listed. Using this combination can have an overall understanding of its place and steps ahead. That has been shown in table (2).

Table2. The model presented

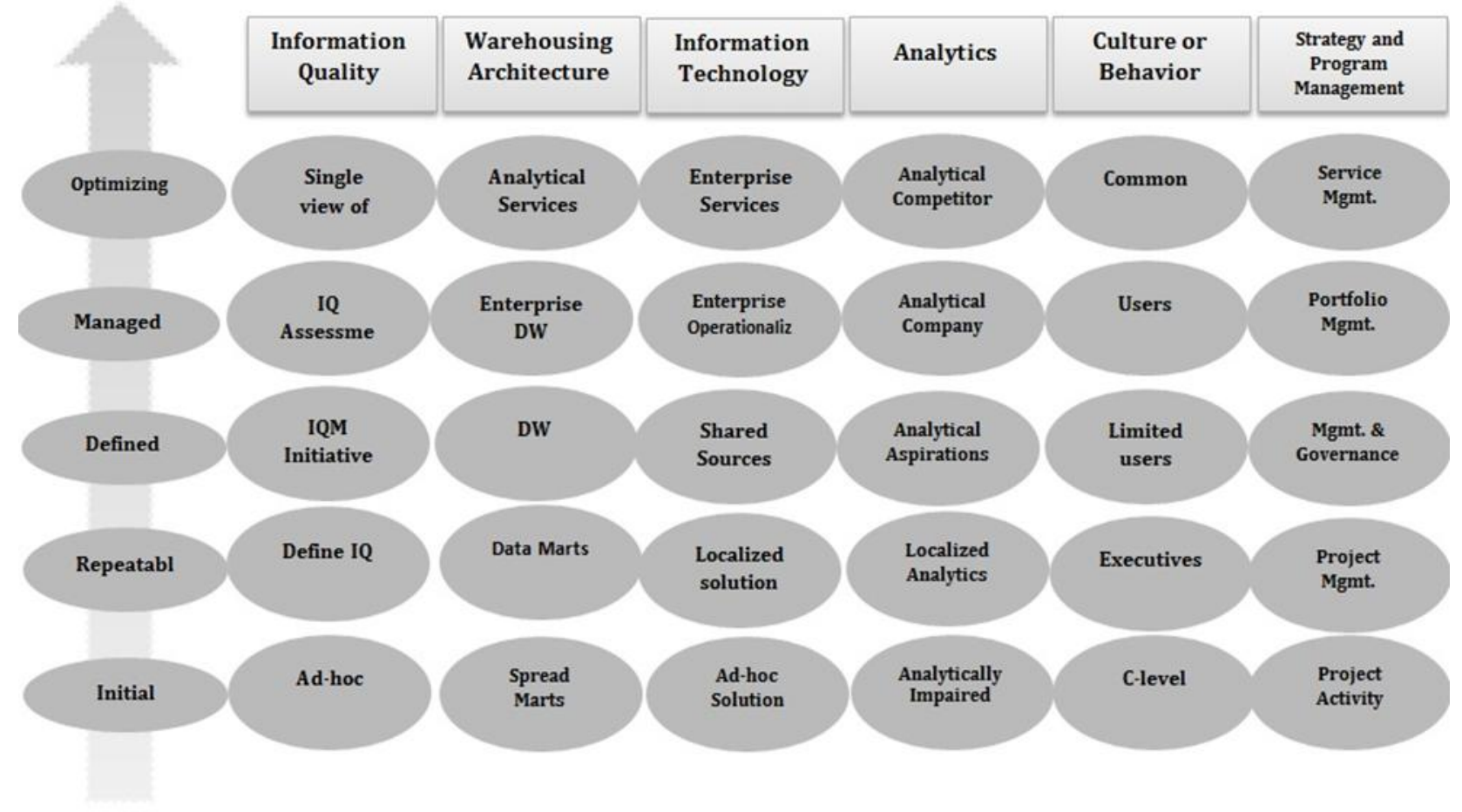

\section{PRIMARY LEVEL}

\section{INFORMATION QUALITY:}

Data quality management process in not standardized or documented. There is not any information about problems which are relating to information quality. Therefore there is not any attempt to evaluate and promote data quality. The organization with try to solve the problem when the problem occurred in information quality.

\section{DATA WAREHOUSE ARCHITECTURE}

Management reports are static reports either weekly, monthly or once every these month for staff to be released. The data they collected, cleaned and then converted to the format that they are going to use them such as personal or group use and transport spread that has the essential role of a data mart or data warehouse. 


\section{INFORMATION TECHNOLOGY}

Many organizations are in the first stages of their investment in business intelligence. Focus on increasing the capabilities needed in this stage is based reporting and analysis. In this stage for the preparation of reports and analysis needed for managers. Will be nonmechanized, manual and gather data from existing sources and there is a very little capacity and capability for disclosing information. At this level reports in finance, marketing and sales of related reports can be successfully performed.

Such as financial reports relating to the sale of department or as area. Business in intelligence solutions focused on first access date is required to solve the needs and there is no integrity in the data storage. the characteristic of these first attempts is for building a data mart an ETL. and often these efforts are to perform manual and non-mechanized in general, operation reports to be static an in flexible and show a limited range of data for a limited set of processes. lack of operational flexibility due to reports of specific users of the tools available to use for your needs.

\section{ANALYSIS:}

The organization has a number of data analysis and management has not interests in analysis of data.

\section{CULTURE AND BEHAVIOR:}

At this level manager believe that business intelligence and operational reports are equal and they don't like the pay more for the lack of in information.

As long as the correct understanding of business intelligence as a strategic recourse isn't available for managers and stability are not attracting customers business intelligence projects which should progress is not so easily.

At this stage people are accustomed to using transport spread mart and are of the major challenges in the next stage is taking the people for from their habits and use of advance tools.

\section{STRATEGY AND PROGRAM MANAGEMENT:}

Case management and content project with limited terms of small scales are available. Managers willingness to invest is limited or absent. Business intelligence projects at this level usually been delayed and is include of paying a lot . usually its reason of some problems is data quality.

Especially if the team manager and project control process for the management and control is not continues. Managers want to invest is limited or maybe in general these isn't any interest for then and also there isn't any budgetary allocation for the project. 


\section{REPEATABLE}

\section{INFORMATION QUALITY:}

All data required for quality production, has been identified and documented. Therefore this level of quality -related information and items needed are classified.

Data warehouse architecture:

If successful of this level may be department data mart is created for each set of processes and the problems are different in other hand. There are implemented in different applications and systems. data mart is in fact a general and a special section on business practices within on organization focuses.

\section{INFORMATION TECHNOLOGY:}

At this level of business focus is still on the increase in reporting and analysis capabilities. at this level users can be limited to the reports and analysis to personalize. Weekly and monthly reports latency due to the use of secret information is less than before. In fact is strange step for business intelligence and data warehouse. At this level of business intelligence provide the basic tools. (Basically the query case, case reports and OLAP analysis who have more power than in the post.) and there is more information about the quality of attention. Users who wish to analyze post data and analysis is related to several weeks, month or years. Helps business improve their performance and application.

\section{ANALYSIS:}

The managers are going to make a plan about analysis. The executive board of the applications are interested in analyze the preliminary analysis.

\section{CULTURE AND BEHAVIOR:}

At this stage most of the users of intelligence services and executive are committee and display data.

\section{STRATEGY AND PROGRAM MANAGEMENT:}

The depend mart program and project management and software development can be with business intelligence. At this level organizations are beginning to recognize and identify critical points for project management. As a regulatory management aims to reduce risk and cost management is considered. While rules and skills for business intelligence projects have been formalized identified, and business intelligence managers have the responsibility of the department. 
Mahdi Sayyadi, Emad Farazmand, Omid Gholami/ TJMCS Vol. 4 №. 2 (2012) 110 - 119

\section{DEFINED}

At this level of data quality is considered as a main activity and to be widely implement in organizations. Information are somewhat timely, reliable and community.

\section{DATA WAREHOUSE ARCHITECTURE:}

Instead of allowing departments to prepare several different not-integrate data mart a business unit of pack valued within a data warehouse. In order to some many within on integrated. Data warehouse, data integration and analysis and better understanding of your business is perceived. An interactive reporting and data warehouse provides a deep analysis. At this level the knowledge insight in the use of capabilities is more than before.

\section{INFORMATION TECHNOLOGY:}

Perhaps this is the biggest change in the level of growth in the use of business intelligence services of temporary or regular users.( Users these who don't need to have a daily basis for data analysis.) These users prefer the information appropriate to their role and work without spending time and energy to get.

Determining a set of standard parameters for a report or dashboard that is suitable for different group of users can be identified. Teams need to important a flexible structure that can respond to change in demand for business intelligence is to access information and also be able to develop an agile development process to support new applications.

\section{ANALYSIS:}

The executive board is committed to respect and resources planning for the construction of extensive analysis capabilities and processes for monitoring is underway.

\section{CULTURE AND BEHAVIOR:}

Behavior view of the services offered can be found. Business intelligence consumers are expanding and while it's not only includes directors and executive committee, but another part of the users is also include.

At this level when people at the managerial level of business intelligence can be found as usual anxious to understanding the application of business intelligence.

\section{STRATEGY AND PROGRAM MANAGEMENT:}

Implementation of department of projects and single-stop application and instead of plant to implement a comprehensive business intelligence that several application of a data model and develop a common platform. Also supervision department manager and a manager of a team led by director of business intelligence can be transmitted through the project budget( such as marketing, sales, finance) are provided. 


\section{MANAGED}

INFORMATION QUALITY:

Criteria have been developed for data quality and data quality is evaluated.

\section{DATA WAREHOUSE ARCHITECTURE:}

Comprehensive data warehouse acts as a comprehensive and integrated machinery an organization of a unique version of the facts and contained are accurate data.

At this level a unified data warehouse and criteria defined in the definition of role among all business units and department are considered.

\section{INFORMATION TECHNOLOGY:}

At this level the score card in order to optimize the execution of business strategies at all hierarchical are used. The organize house are not only the processes by monitoring dash beads are also using a scare card, the management are considered and compared. Scare card for the users to understand and improve business activity increases. Also mar organization are beginning to use predictive modeling tools and high-level sales finance departments can have the user desires to predict the future with high accuracy.

\section{ANALYSIS:}

The organization is able to predict consequences. Ability to analyze large amounts of the directors and executive committee is to attract analysis capabilities. across The business will start to develop.

\section{CULTURE AND BEHAVIOR :}

Business intelligence is a huge rage of consumers in the most critical and important decisions is critical.

Strategy and program management:

At this level of project management, business intelligence and integrated management strategy are in the same line. Organization for business intelligence has developed a mentioning model. At this level of funding is common informatics an business intelligence.

\section{OPTIMIZATION}

\section{INFORMATION QUALITY:}

Source of information quality problems are I identified and measures for improving the quality of information are carried out continuously information are timely reliable and comprehensive. 


\section{DATA WAREHOUSE ARCHITECTURE:}

At this level of comprehensive data warehouse is common to improve its efficiency. At this stage, the data warehouse is a basic tool that will disappear behind other business intelligence services.

\section{INFORMATION TECHNOLOGY:}

The level of business intelligence capacity to service the conversion cycle is completed. At this level of organization of service-oriented architecture for rapid development uses. With the rotation of web-based user inter face capabilities of business intelligence developers can be in all application regardless of platform an programming language are available.

\section{ANALYSIS}

Analysis capability for the organization and provides additional benefits organizations to continuously focus on housing and measure in order to automate processes is underway.

\section{CULTURE AND BEHAVIOR:}

The organization called for more investment in business intelligence and being to create a powerfully solution that respond with high accuracy is required to have service.

The correlation between the level of business and business intelligence team to reach its peak and business intelligence as a key source of profitability is considered.

\section{STRATEGY AND PROGRAM MANAGEMENT:}

at this level, Organizations must continuously using new tools and technologies in the field of business intelligence capabilities increase. This level of investment in business intelligence is becoming a key problem and an alliance between business and business intelligence. Team to reach its peak and also the budget project is separately.

\section{CONCLUSION}

All models so far proposed for business intelligence has been found on a common premise with the premise that organizations fully implementing business intelligence and consider with all of its dimensions, however some of the organization cause of some reasons including budget deficits lack of skilled labor, Time of project implementation, the need for same aspects of business intelligence and problems in the implementation plan to implement only some of their business intelligence capabilities. Organization should consider these points and to walk with their intentions table presents and in the article which shows at a glance most model can be presented to persuade shareholders and investors with investment in the sector which can be taken larger steps and organization steps.

Model of business intelligence capabilities in iran public and private organization in comparison with other areas located in lower level and can say that only some institutions 
take managers know a little about this field and it's capabilities. This take of familiarity and distance is a result of utility the benefits of business intelligence. This article can be as an introduction which has been filled with ups and downs. It is hoped that further research be done in future and scope of business intelligence in organizations and institutions within the countries studied.

\section{REFERENCE}

[1] Bräutigam, D., Gerlach, S. \& Miller, G. 2006, Business Intelligence Competency Centers. Hobo-ken: John Wiley \& Sons, Inc.

[2] David, L. The Benefits of Embedding High Value Business Intelligence, white paper, Sponsored by Business Objects, SAP company.

[3] Paulk, M. C., Curtis, B., Chrissis, M. B. \& Weber, C. B. (1993). "Capability Maturity

Model for Software," Version 1.1, Software Engineering Institute, Carnegie Mellon University.

[4] Hewlett Packard (HP). 2009. "The HP Business Intelligence Maturity Model: Describing the BI journey". Hewlett-Packard Development Company, L.P

[5] Eckerson, W.W. 2009. "TDWI's Business Intelligence Maturity Model." The Data Warehousing Institute, Chatsworth (2009)

[6] Gangadharan, G. R. \& Swami, S. N. (2004). "Business Intelligence Systems: Design and Implementation Strategies," Proceedings of the 26th International Conference on Information Technology Interfaces (ITI). 10 - 10 June 2004, Croatia, 139-144.

[7] Hagerty J. 2006. "AMR Research 's Business Intelligence / Performance Management Maturity Model“, Version 2. Most. 2006.

[8] Baškarada, S., Koronios, A. \&Gao, J. (2007). Assuring Enterprise-Wide Information Quality Management Capability Maturity, Technologies for Business Information Systems, Abramowicz W. and Mayr H. C.(ed). Springer: pp. 353-363.

[9] Davenport, T. H. \& Harris, J. G. (2007). Competing on Analytics: The New Science of Winning, Harvard Business School Press. 